NBER WORKING PAPER SERIES

\title{
OVERSEAS DEPLOYMENT, COMBAT EXPOSURE, AND WELL-BEING IN THE 2010 NATIONAL SURVEY OF VETERANS
}

\author{
Ryan D. Edwards \\ Working Paper 18227 \\ http://www.nber.org/papers/w18227 \\ NATIONAL BUREAU OF ECONOMIC RESEARCH \\ 1050 Massachusetts Avenue \\ Cambridge, MA 02138 \\ July 2012
}

I am grateful to Tom Garin and Mike Grierson at the U.S. Department of Veterans Affairs, to Cary Haver at the Institute of Medicine for assistance in obtaining and understanding the public file of the 2010 National Survey of Veterans, and to seminar participants at Lafayette College for helpful comments. All analysis, opinions, and any mistakes expressed in this paper are solely my own and do not reflect the perspectives or positions of any other group or institution. I declare no conflicts of interest nor external funding sources. The views expressed herein are those of the author and do not necessarily reflect the views of the National Bureau of Economic Research.

NBER working papers are circulated for discussion and comment purposes. They have not been peerreviewed or been subject to the review by the NBER Board of Directors that accompanies official NBER publications.

(C) 2012 by Ryan D. Edwards. All rights reserved. Short sections of text, not to exceed two paragraphs, may be quoted without explicit permission provided that full credit, including $\odot$ notice, is given to the source. 
Overseas Deployment, Combat Exposure, and Well-Being in the 2010 National Survey of Veterans

Ryan D. Edwards

NBER Working Paper No. 18227

July 2012

JEL No. H56,I1,N42

\begin{abstract}
Recent military engagements in Iraq (OIF) and Afghanistan (OEF) raise questions about the effects on service members of overseas deployment, which can include service in a combat or war zone, exposure to casualties, or both. The 2010 National Survey of Veterans, which asked a broad cross section of living veteran cohorts about deployment to OEF/OIF and combat exposure, provides some new insights into short and long-term relationships between characteristics of military service and outcomes. Analysis of these data suggests that the impacts of deployment and combat on the current socioeconomic well-being of returning OEF/OIF veterans may be relatively small, but the effects of combat exposure on self-reported health and other nonpecuniary indicators of their well-being appear to be negative. Among older veteran cohorts, where there is clearer sorting into treatment and control groups because of strong variation in combat exposure by year of birth, patterns are broadly similar. These results are consistent with a veterans compensation system that replaces lost earnings but does not necessarily compensate for other harms associated with combat exposure such as mental health trauma.
\end{abstract}

Ryan D. Edwards

Department of Economics

Queens College, CUNY

Powdermaker Hall 300-S

Flushing, NY 11367

and NBER

redwards@qc.cuny.edu 


\section{Introduction}

The impacts of military service on individuals and families are a perennial topic of interest to researchers and policymakers, and they have become more salient recently as a result of the unprecedented pace of deployments to Iraq and Afghanistan as part of Operation Iraqi Freedom (OIF) and Operation Enduring Freedom (OEF). By April of 2009, the number of service members ever deployed had reached 1.9 million (Institute of Medicine, 2010). Data from the 2010 National Survey of Veterans (NSV), shown in Table 1 and described in more detail below, suggests that by early 2010 there were between 1.5 and 1.8 million veterans of the conflicts in Iraq and Afghanistan who had returned to civilian life, out of about 2.5 million veterans of the Post-9/11 era. ${ }^{1}$

There is a vast body of research evaluating the health and well-being of earlier cohorts of veterans, and an array of studies have focused broadly on outcomes among Post-9/11 veterans, including the ongoing Millennium Cohort Study (MCS) (Smith et al., 2007) and the Invisible Wounds effort and others by the RAND Corporation (Tanielian and Jaycox, 2008). But aside from the MCS, which suffers from its own limitations of scope, there are relatively few data sources that can reveal the impacts of deployment or other characteristics of military service on a broad array of socioeconomic and health outcomes. An exception is the National Longitudinal Survey of Adolescent Health, which Cesur, Sabira and Tekin (2011) utilize to reveal significant effects of combat deployment on mental health outcomes among young veterans.

The 2010 National Survey of Veterans is the latest in a series of public datasets that provide assessments of health and socioeconomic well-being for living veterans in households. It included 753 veterans of the Post-9/11 era, of whom 453 reported being deployed in support of OEF/OIF. Although the 2010 NSV is not a comprehensive survey of health,

\footnotetext{
${ }^{1}$ There are two estimates of the total population of veterans deployed in support of OEF/OIF because separate questions in the NSV asked the veteran to identify his or her period of service and then whether he or she had deployed to OEF/OIF. As shown in Table 1, 112 veterans in the survey indicated they had deployed while not indicating they had served during the Post-9/11 period. The phrasing of the question, shown in section 2.2 , suggests that some veterans may have thought that by answering yes they were registering their political or moral support for OEF/OIF, rather than deploying in support of OEF/OIF. In my regression analysis of deployment to $\mathrm{OEF} / \mathrm{OIF}$, I restrict the data universe to veterans who reported serving in the Post-9/11 era. By comparison, data from the 2010 American Community Survey suggest there were 3,326,129 veterans who served in 2001 or later (Ruggles et al., 2010).
} 
Table 1: Veterans by period of service in the 2010 National Survey of Veterans

\begin{tabular}{|c|c|c|c|c|c|c|c|c|}
\hline $\begin{array}{l}\text { Period of } \\
\text { service }\end{array}$ & Dates & $\begin{array}{r}\text { Raw } \\
\text { count }\end{array}$ & $\begin{array}{r}\text { Estimated } \\
\text { national } \\
\text { population }\end{array}$ & $\begin{array}{l}\text { Avg. } \\
\text { year of } \\
\text { birth }\end{array}$ & $\begin{array}{l}\text { Pct. } \\
\text { male }\end{array}$ & $\begin{array}{l}\text { Pct. in } \\
\text { combat } \\
\text { or war }\end{array}$ & $\begin{array}{r}\text { Pct. exp. } \\
\text { to dead } \\
\text { or dying }\end{array}$ & $\begin{array}{r}\text { Avg. } \\
\text { VA } \\
\text { disab. }\end{array}$ \\
\hline Pre-WWII & Nov 1941 or earlier & 34 & 89,503 & 1921.2 & 100.0 & 74.8 & 55.4 & 7.1 \\
\hline WWII & Dec 1941 - Dec 1946 & 887 & $1,876,041$ & 1923.7 & 96.2 & 54.2 & 44.9 & 3.9 \\
\hline Peacetime 1 & Jan 1947 - Jun 1950 & 165 & 362,980 & 1928.1 & 99.1 & 30.9 & 30.7 & 2.5 \\
\hline Korea & Jul 1950 - Jan 1955 & 1,137 & $2,388,470$ & 1931.2 & 97.5 & 31.0 & 26.0 & 3.2 \\
\hline Peacetime 2 & Feb 1955 - Jul 1964 & 1,638 & $3,819,478$ & 1937.8 & 98.4 & 14.0 & 17.7 & 2.9 \\
\hline Vietnam & Aug 1964 - Apr 1975 & 3,661 & $7,312,478$ & 1946.7 & 97.4 & 43.6 & 44.0 & 7.0 \\
\hline Peacetime 3 & May 1975 - Jul 1990 & 1,801 & $5,937,772$ & 1958.3 & 85.2 & 25.2 & 31.1 & 8.0 \\
\hline Gulf War 1 & Jul 1990 - Aug 2001 & 1,134 & $4,090,311$ & 1965.1 & 82.2 & 45.2 & 41.3 & 12.4 \\
\hline Post-9/11 & Sep 2001 or later & 753 & $2,545,940$ & 1972.4 & 82.0 & 60.9 & 48.2 & 14.8 \\
\hline \multicolumn{2}{|c|}{ Deployed to OEF/OIF } & 565 & $1,819,195$ & 1970.2 & 86.5 & 88.1 & 63.0 & 12.8 \\
\hline \multicolumn{2}{|c|}{ Deployed to OEF/OIF \& Post-9/11 } & 453 & $1,467,529$ & 1973.8 & 87.3 & 91.7 & 63.6 & 13.5 \\
\hline
\end{tabular}

Sources: 2010 National Survey of Veterans and author's calculations. The universe is all veterans. Those who report service during multiple periods appear multiple times and affect the averages for each period with which they self-identify. Statistics are computed with survey weights. OEF/OIF stands for Operation Enduring Freedom, conducted mostly in Afghanistan starting in October 2001, and Operation Iraqi Freedom, beginning in March 2003.

See the text for a discussion of the variables measuring service in a combat or war zone and exposure to dead, dying, or wounded people. The average VA disability rating is calculated by assigning zero ratings to all veterans who report no VA disability rating.

employment, or income, the data provide a unique look at the current well-being of many veterans of different eras. In particular, the 2010 NSV reveals how the self-reported wellbeing of veterans varies with self-reported characteristics of military service like deployment to OEF/OIF and two key outcomes associated with deployment: service in a combat or war zone, and exposure to dead, dying, or wounded people.

The basic research and surveillance questions we can begin to assess with these data are how deployment and combat exposure among Post-9/11 veterans may be associated with their well-being shortly after separation from the military. And because all veterans in the 2010 NSV are asked about their combat exposure, it is possible to formulate expectations about the potential longer-term impacts of combat on Post-9/11 veterans based on the experience of earlier veteran cohorts, although such comparisons are inherently speculative.

An advantage of this second strategy is that it can leverage the identification power of earlier natural experiments in combat exposure across birth cohorts that better identify treatment and control groups. Because young men have traditionally born the burden of going to war, and because even long wars have discrete beginnings and endings, both military service and combat exposure has varied sharply among men of the conscription era, in large part because they ceased to be drafted into combat when wars ended. Data in the 2010 
NSV confirms these strong patterns among earlier veteran cohorts, but at least among the Post-9/11 veterans who had separated prior to 2010 and were sampled, such patterns are nonexistent and cannot be leveraged for identification. In this analysis of the effects of deployment and combat among Post-9/11 veterans, the best I can do is use propensity-score matching to attempt to correct for nonrandom selection into treatment and control. That the results are broadly consistent with comparable ordinary least squares (OLS) results, and with instrumental variables (IV) estimates of the effects of combat exposure on outcomes among veterans from many birth cohorts, offers a modicum of reassurance that selection bias may not be overwhelmingly large. In focusing on deployment among veterans I am avoiding the well-known and potentially thornier problem of selection into the military (Angrist, 1990; Angrist and Krueger, 1994). But whether selection into deployment given military service is any weaker than selection into service is unclear.

Estimation results suggest that deployment to OEF/OIF appear to have had few direct effects yet on the current socioeconomic well-being of Post-9/11 veterans, but the subsample is small and standard errors are large. Utilization of educational benefits may be higher, as might employment rates. But deployment is also a significant risk factor for service in a war zone and for exposure to casualties, both of which are strongly associated with current self-reported health, but in an interesting twist, not with physical disability. These patterns are consistent with a disability compensation system designed to replace lost earnings, and with mental health trauma associated with combat exposure among returning OEF/OIF veterans, which is suggested by the results of Cesur, Sabira and Tekin (2011).

Among veterans of all ages in the 2010 NSV, both OLS and IV regressions reveal significant impacts of service in a war zone and of exposure to casualties on an array of outcomes, but they often take opposite sign. Neither seem to affect household income at all, which is further evidence of a functioning disability compensation program, but service in a war zone often improves or does not affect outcomes while exposure to casualties, which displays much independent variation, tends to harm them. This is most evident in patterns of marriage, divorce, and homeownership, and less so for self-reported health and disability, both of which are strongly reduced by exposure to casualties but basically unaffected by service 
in a war zone. Robustness of a key result across estimation strategies and samples, namely that exposure to casualties appears to have negative impacts on nonpecuniary aspects of well-being, is a relatively clear indication of one type of lifelong burden of military service. There is also some evidence of lifelong benefits associated with military service, for veterans who served in war zones but were able to avoid exposure to casualties. But whether these effects could have improved outcomes for nonveterans, i.e., whether military service per se might improve some outcomes, is far from clear and impossible to answer with these data.

The paper proceeds as follows. In section 2, I describe the dataset in greater detail. I provide an analytical framework in section 3, and I formulate several testable regression models of outcomes on deployment, combat, and characteristics. In section 4, I present and discuss evidence on deployment, combat, and outcomes among Post-9/11 veterans first using simple mean differences, then propensity-score adjusted differences, and then multivariate regression. Section 5 presents comparable results for all veterans employing an instrumental variables strategy that leverages sharp differences in combat exposure by year of birth. In section 6 , I discuss conclusions and limitations.

\section{The 2010 National Survey of Veterans}

\subsection{Survey design}

The 2010 National Survey of Veterans (NSV), the sixth in a series of repeated cross sections first surveyed in 1977, was conducted between October 16, 2009, and March 19, 2010 by Westat on behalf of the U.S. Department of Veterans Affairs (VA) (Westat, 2010). Each one of six subcomponent surveys in the 2010 NSV targeted a different veteran or military subpopulation: (1) all veterans who had separated from service; (2) demobilized National Guard or Reserves; (3) active duty service members; (4) spouses of living veterans; (5) spouses of active duty service members; and (6) surviving spouses of deceased veterans. My focus in this study is on the survey of all veterans.

The 2010 NSV veterans questionnaire was mailed out to 14,163 recipients in households, 
of whom 8,710 or about 61 percent responded. ${ }^{2}$ Recipients were identified through a tiered process in which the first stratum consisted of users of VA services or retirees with addresses on file with VA or DOD, matched to a vendor's random sample of 1.8 million postal addresses (Westat, 2010). The second stratum included matched individuals present in the DOD's Prior Service Military Address Files but not present in VA or retiree files. A third stratum included all other unmatched postal addresses from the initial random sample.

Westat computed sampling weights to adjust for selection probability and item nonresponse, using the VA's VetPop2007 demographic data, which are derived from Census surveys of the civilian noninstitutional population, as population controls. ${ }^{3}$ Westat also constructed 100 replicate weights using a grouped jackknife method. In my analysis, I use both the final sample weight and the 100 jackknife replicate weights to produce point estimates and standard errors. ${ }^{4}$ Figure 1 shows estimates of the national veteran population by year of birth derived from the $2010 \mathrm{NSV}$.

\subsection{Scope}

Like its predecessors, the 2010 NSV was primarily designed to gauge veterans' awareness and use of VA programs, but the survey also collected demographic characteristics in order to adjust for selection and nonresponse. In addition, the survey also asked about socioeconomic characteristics like the household's total income plus transfers, ${ }^{5}$ homeownership,

\footnotetext{
${ }^{2}$ Respondents were initially asked via mailout to complete an online version of the survey. After one subsequent reminder mailout, nonrespondents were mailed the paper questionnaire.

${ }^{3}$ The universe thus presumably excludes veterans who are incarcerated or in nursing homes, and they probably exclude or undercount homeless veterans. Estimates of the marginal effects of deployment and combat on outcomes based on these data will miss extreme events like felony convictions, significant disability requiring nursing care, or homelessness.

${ }^{4}$ Westat employed the JK1 routine in their proprietary software WesVar, whose documentation is available online. I use the suite of svy commands in Stata 12.0 to estimate models using survey data. Estimation routines in Stata require the final sample weight in addition to the 100 jackknife replicates. Although the final sample weight was missing from the public file of the $2010 \mathrm{NSV}$, the documentation for WesVar's JK1 routine shows that the simple average over the 100 replicates for each observation is equal to the final sample weight. Thus I reconstructed the final sample weight as the average (including the zeros) of the replicate weights.

${ }^{5}$ In the survey's income module, veterans were first asked whether or not they or resident family members had received any income during the past year from a list of 10 sources beginning with labor earnings and capital asset income and ending with government transfers like VA disability compensation and any private transfers. Then they were asked to indicate the total amount received last year from those sources by choosing among a set of ranged responses. I measure dollars of household income plus transfers using the middle value within the reported range.
} 
Figure 1: Estimates of U.S. veterans by year of birth

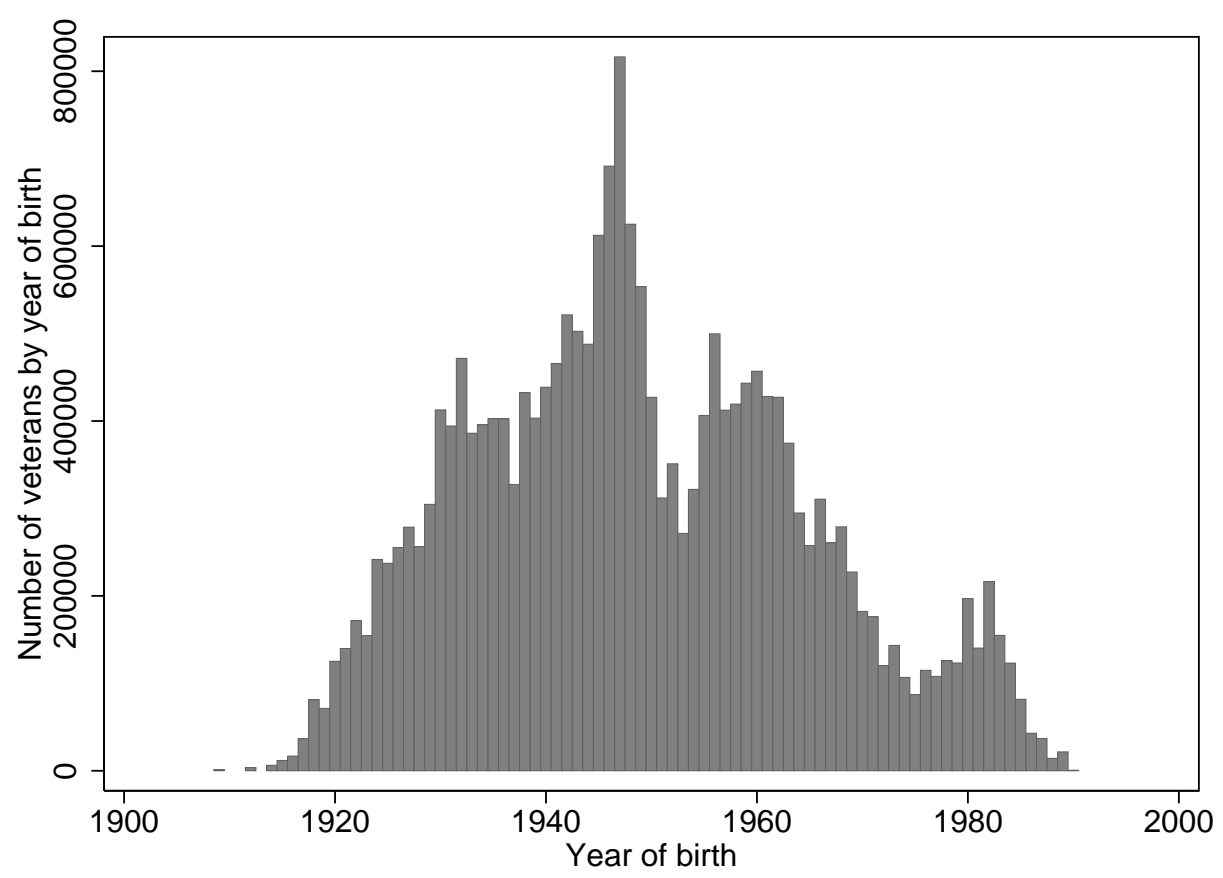

Source: 2010 National Survey of Veterans. Counts are computed with survey weights.

employment status, and education. It also asked several questions about the veteran's health and disability status and VA disability rating, ${ }^{6}$ and the survey began with several questions about the veteran's military service.

The 2010 NSV is the first public study to ask specifically about deployment to Iraq or Afghanistan in the conflicts following the events of September 11, 2001. As is common in Census data, the NSV ascertained period of service on active duty by presenting a set of checkboxes including one for the Post-9/11 era. Then the survey asked about deployment:

A4. Did you deploy in support of Operation Enduring Freedom (OEF) or Operation Iraqi Freedom (OIF)? (Yes/No)

\footnotetext{
${ }^{6}$ The questionnaire asks the veteran to report the VA disability rating using a set of ranged responses similar to income, and I measure the VA disability rating using the middle of the reported range. I assign a zero rating to veterans who report not having a VA disability rating.
} 
There are no comparable questions about deployment to war theaters from previous eras. The NSV then asked the years in which the veteran first entered and was last released from active duty ${ }^{7}$ before presenting two questions about exposure to combat or war zones and to casualties, both of which I will refer to as "combat exposure" questions:

A7. Did you ever serve in a combat or war zone? [NOTE: Persons serving in a combat or war zone usually receive combat zone tax exclusion, imminent danger pay, or hostile fire pay.] (Yes/No)

A8. During your military service, were you ever exposed to dead, dying, or wounded people? (Yes/No)

There is some overlap but far from a one-to-one correspondence between these three binary indicators of deployment and combat exposure, as shown in Table 2. The top panel in the table cross-tabulates responses to questions A7 and A8 among veterans who reported deployment in support of OEF/OIF. ${ }^{8}$ Almost 10 percent of veterans reporting such deployment indicated they had not served in a combat or war zone. Among the 91.6 percent who had, 31.1 percent or about a third reported no exposure to dead, dying, or wounded people. The remaining 60.5 percent reported exposure to casualties. This is large relative to other veteran cohorts. Some OEF/OIF veterans may have been exposed to casualties during earlier conflicts and not during OEF/OIF; because the question asks about lifetime exposure, there is no easy way to tell. The middle and bottom panels of Table 2 repeat the analysis for Post-9/11 veterans and for all veterans. The comparison reveals considerably higher self-reported rates of service in a combat or war zone and exposure to casualties

\footnotetext{
${ }^{7}$ I measure total years on active duty as the difference between these two reported years. This is probably an overestimate of the true time spent on active duty, but while the bias is likely to vary across different classes of veterans, i.e., career military or conscripts, it is unlikely to vary within classes, which would be worrisome.

${ }^{8}$ Because the questionnaire asked about period of service (question A3) and deployment in support of OEF/OIF (A4) separately, it was possible for veterans to report the latter but not the former, which presumably is impossible. There are 111 such observations in the data, 108 of which also include data on the most recent year of separation from active duty (A6). Only 13 of the latter are 2001 or later, suggesting that many veterans may have misread or misunderstood "deploy in support of" in question A4 to mean something other than deployment, perhaps feelings of solidarity. In my analysis of the effects of deployment to OEF/OIF, I effectively drop these observations by conditioning on veterans' identifying themselves as belonging to the Post-9/11 era.
} 
Table 2: Percent exposed to combat zones and casualties by cohort

\begin{tabular}{ll|rrr} 
& & \multicolumn{4}{|c}{$\begin{array}{c}\text { Ever exposed to dead, } \\
\text { dying, or wounded }\end{array}$} \\
\hline Deployed to OEF/OIF & & No & Yes & \multicolumn{1}{c}{ Total } \\
\hline Ever serve in a & No & 5.3 & 3.1 & 8.4 \\
combat or war zone & Yes & 31.1 & 60.5 & 91.6 \\
& Total & 36.4 & 63.6 & 100.0 \\
& & & & \\
\hline Post-9/11 veterans & & No & Yes & Total \\
\hline Ever serve in a & No & 30.5 & 8.8 & 39.3 \\
combat or war zone & Yes & 21.1 & 39.6 & 60.7 \\
& Total & 51.6 & 48.4 & 100.0 \\
& & & & \\
\hline All veterans & & No & Yes & Total \\
\hline Ever serve in a & No & 55.5 & 10.6 & 66.1 \\
combat or war zone & Yes & 10.7 & 23.2 & 33.9 \\
\multicolumn{1}{l|}{} & Total & 66.2 & 33.9 & 100.0 \\
\hline \hline
\end{tabular}

Sources: 2010 National Survey of Veterans and author's calculations. The universe in the top panel is Post-9/11 veterans; in the bottom panel, it is all veterans. Percentages are computed with survey weights. See the text for a discussion of the variables.

among recent veterans, no doubt a byproduct of the transition to the All-Volunteer Force $(\mathrm{AVF})$ and a larger share of career military serving during an era with two long wars.

\subsection{Comparisons of veteran cohorts}

Table 1 displays a selected set of average characteristics among veterans in the $2010 \mathrm{NSV}$ by period of service, which is shown along the rows. ${ }^{9}$ Combat exposure rates for Post-9/11 veterans and those deployed in support of OEF/OIF differ slightly from those shown in Table 2 because some veterans answered only one of the two combat exposure questions. As one would expect, surviving veterans from earlier periods are older and more often male, while patterns in combat exposure and VA disability are more complicated. Service during a major conflict is naturally associated with higher levels of each, but there is also some evidence of U-shaped trend through age or year of birth. Very old and very young veterans report higher VA disability ratings and more combat exposure than middle-aged veterans. This pattern could reflect any combination of several factors: trends in average exposure to combat, differential survival favoring older veterans with greater access to VA care and benefits, differential screening or detection of disability, or changes in the disability rating

\footnotetext{
${ }^{9}$ Veterans who report multiple periods appear in multiple rows in the table and contribute to the averages for each period they identify.
} 
system.

Figure 2 plots the percent of veterans who report combat exposure against the year of their birth, revealing a similar U-shaped pattern punctuated by a spike in combat exposure among Vietnam veterans born mostly in the late 1940s. Especially prior to the AVF period, birth cohorts of veterans who were in their late teens and early twenties at the time of major military conflicts were disproportionately exposed to combat. This is similar to patterns of elevated military service among all male civilians in the same birth cohorts because of the draft, which ended in 1973 (Angrist and Krueger, 1994; Card and Lemieux, 2001). It is also reminiscent of patterns in combat exposure by year of birth among veterans and nonveterans in the National Vietnam Veterans Readjustment Study (Rohlfs, 2010).

Figure 2: Veterans' exposure to combat and casualties by year of birth

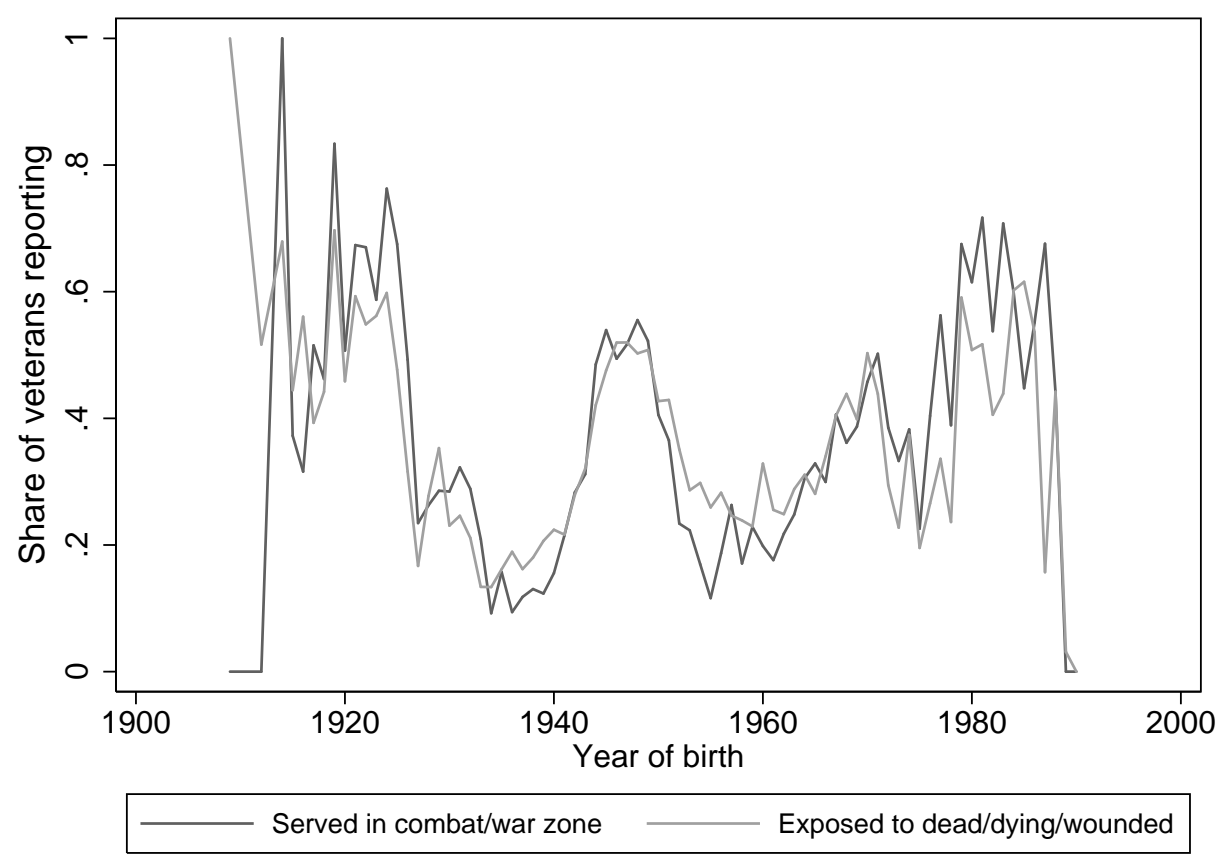

Source: 2010 National Survey of Veterans. Statistics are computed with survey weights. See the text for a discussion of the variables measuring service in a combat or war zone and exposure to dead, dying, or wounded people.

These relatively sharp differences in combat exposure across otherwise similar birth 
cohorts are likely to identify differences in outcomes that are directly attributable to combat exposure rather than to confounding factors. Unfortunately, rates of combat exposure by birth cohort among veterans of the Post-9/11 period, who were the only group at risk of deployment to OEF/OIF, follow no such clear pattern. This is shown in Figure 3, which depicts noisy but basically flat rates of combat exposure by year of birth among Post-9/11 veterans in the $2010 \mathrm{NSV}$.

Figure 3: Post-9/11 veterans' exposure to combat and casualties by year of birth

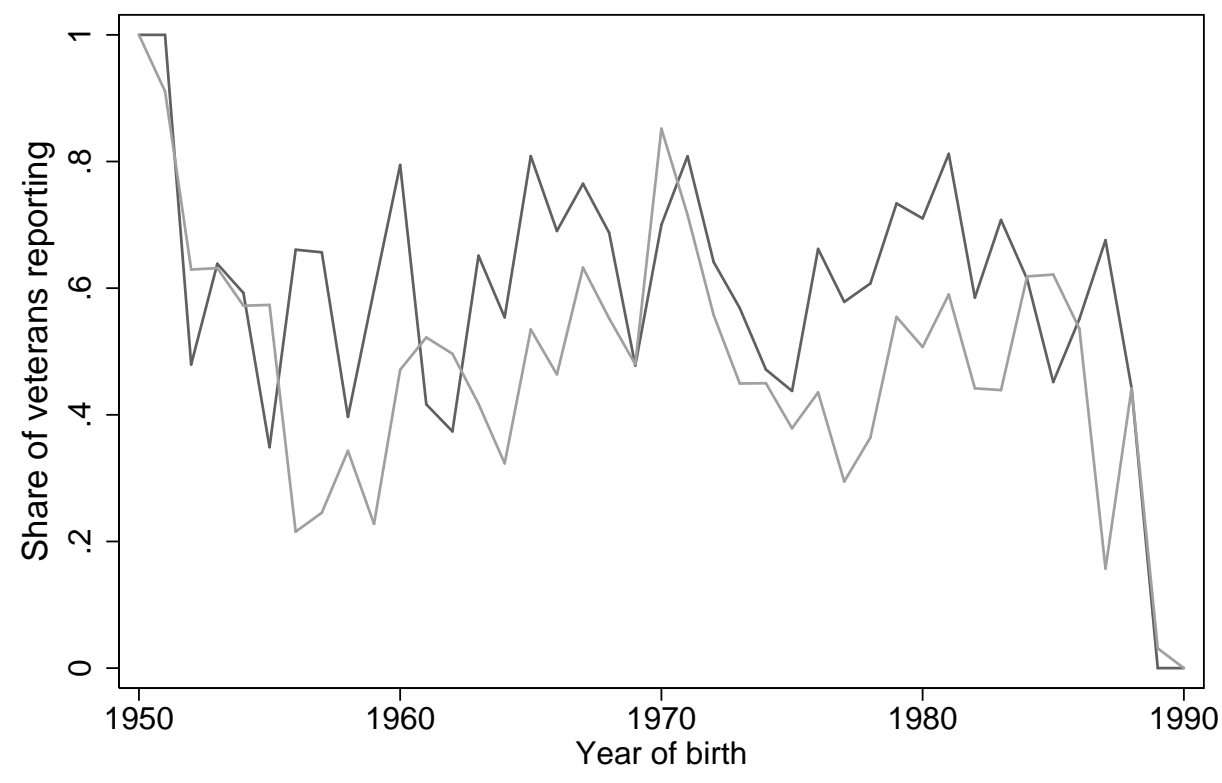

Served in combat/war zone

Exposed to dead/dying/wounded

Source: 2010 National Survey of Veterans. Statistics are computed with survey weights. The sample is restricted to veterans who reported serving during the Post-9/11 period. See the text for a discussion of the variables measuring service in a combat or war zone and exposure to dead, dying, or wounded people.

\section{Analytical framework}

Military service may represent a treatment that affects socioeconomic and health outcomes for service members and families; or it may reflect selection into the military along a variety 
of characteristics like health, ability, budgets, and preferences; or both of these stories could be true (MacLean and Edwards, 2012). To the extent that it is a treatment, military service could either positively or negatively affect many outcomes. ${ }^{10}$ The specific treatments of overseas deployment and combat exposure seem more likely to bring harms than benefits, but their net effects on financial and other outcomes might be zero or positive, given that the veterans compensation system is designed to replace earnings lost to service-related disabilities (Institute of Medicine, 2007), and that service is voluntary. The 2010 NSV provides a unique opportunity to examine how deployment may be associated with a broad array of socioeconomic outcomes, how deployment and combat exposure are related to each other and to outcomes among Post-9/11 veterans, and how combat exposure is related to later-life outcomes among older veteran cohorts.

Whether there is selection into deployment or combat given military service is the main question this and other studies of veterans must confront. If service members were randomly assigned to these treatments, then a simple comparison of means between groups could reveal the average treatment effect. But deployment is likely to be endogenous, reflecting a command assessment of a unit's effectiveness, which is based on the characteristics of service members and their units.

My empirical strategy begins with examining how a set of individual and family outcomes $y_{i}$ for each Post-9/11 veteran $i$ vary across deployment to OEF/OIF. A simple comparison of means reveals a number of significant differences, including variation in basic demographics. A commonly used statistical method to deal with nonrandom assignment is propensity score matching (Rosenbaum and Rubin, 1983), which adjusts for the probability of assignment to treatment and control groups based on observables. Relevant observables in the NSV are demographic characteristics and branch and length of service. In these data, I find that

\footnotetext{
${ }^{10}$ Service may enhance self-control or patience, characteristics that would improve socioeconomic and health outcomes. It also imposes new peer groups, which could be good or bad for health and other outcomes. Exposure to combat can result in physical and psychological wounds, which may reduce wellbeing directly and indirectly through reduced earnings. But if survived, combat or service in a war zone might also produce feelings of optimism, control, or invincibility. Deployment may strain family relationships and reduce a range of individual and family outcomes, and it could also affect future employment for reservists, either through lost experience or strategic responses by employers. Compared to time spent in the civilian labor force, military service either could enhance or reduce earnings depending on whether service adds or subtracts skills or experience relevant for the civilian labor market.
} 
propensity score matching produces estimates of the effects of deployment that are similar to mean differences. What emerges from both types of analysis is that deployment is strongly associated with exposure to combat or war zones and with exposure to casualties. This suggests that deployment could affect outcomes through the combat exposure variables and motivates modeling the latter as treatments.

With that in mind, I next turn to multivariate regression analysis of the set of outcomes $y_{i}$ by nesting several reduced-form linear models:

$$
\begin{aligned}
& y_{i}=\alpha+\beta \cdot \text { deploy }_{i} \quad+X_{i} B+\epsilon_{i} \\
& =\alpha+\beta \cdot \text { deploy }_{i}+\gamma \cdot \text { combat }_{i}+\delta \cdot \text { casualty }_{i} \quad+X_{i} B+\epsilon_{i} \\
& =\alpha+\beta \cdot \text { deploy }_{i}+\gamma \cdot \text { combat }_{i}+\delta \cdot \text { casualty }_{i}+H_{i} C \quad+X_{i} B+\epsilon_{i}
\end{aligned}
$$

where $\beta, \gamma$, and $\delta$ are the marginal effects on $y_{i}$ of deployment in support of OEF/OIF, service in a combat or war zone, and of exposure to dead, dying, or wounded. The vector $X_{i}$ measures demographic characteristics, and the vector $H_{i}$ measures health and disability. Table 3 lists the full set of these covariates for each outcome $y_{i}$. Health is likely to be independently important for other non-health outcomes $y_{i}$ but it may also be the channel through which deployment and combat exposure affects $y_{i}$. Short of pursuing a structural modeling approach, which would be difficult with these data, it is helpful to nest these reduced-form models in order to best ascertain proximate effects and transmission channels.

Initially, I estimate equations (1)-(3) using ordinary least squares (OLS), so that $\epsilon_{i}$ is assumed to be a white-noise, conditionally homoscedastic error term. ${ }^{11}$ The OLS estimates of $\beta, \gamma$, and $\delta$ are identified by the conditional cross-sectional variation in deployment, which is only random if all the characteristics relevant for outcomes and deployment are included in $X_{i}$ and not in $\epsilon_{i}$. Given the limited scope of the NSV and thus of $X_{i}$, this assumption seems likely to be violated.

\footnotetext{
${ }^{11}$ Although we are interested in several outcomes $y_{i}$ that are dichotomous, I proceed with the linear probability model because I am primarily concerned with consistent estimates of $\beta$, the causal effect of deployment on the outcome, and deployment and other endogenous regressors are themselves dichotomous. The econometrics literature does not speak with one voice on this issue, but Angrist (2001) argues that two-stage least squares is adequate for causal inference regarding marginal effects.
} 
Table 3: Covariates included in multivariate regressions

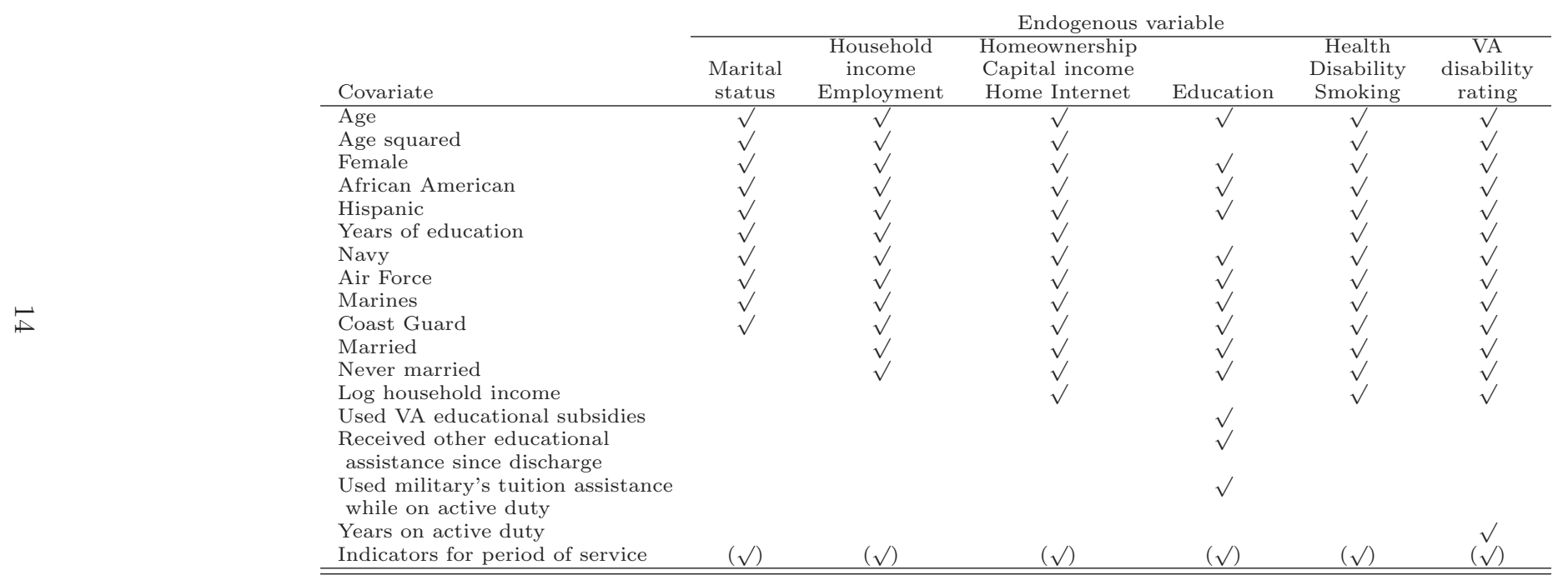

Note: All covariates are categorical indicator variables except age, age squared, years of education, log household income, and years on active duty, which are all continuous. Indicators for period of service are not included in the Post-9/11 regressions modeling the effect of deployment to OEF/OIF on outcomes, but the indicators are included in regressions of outcomes on the combat exposure variables among all veterans. See footnote in the text for details on variable construction. 
But a feasible strategy with these data is to draw identification off of the sharp variation in combat exposure among older birth cohorts of veterans that is shown in Figure 2. I construct instrumental variables $z_{1}$ and $z_{2}$ equal to the proportions of the year-of-birth cohort in the 2010 NSV reporting exposure to a combat or war zone and exposure to casualties, and I estimate the following using two-stage least squares (2SLS) on the full sample of veterans of all eras:

$$
\begin{aligned}
y_{i} & =\alpha+\gamma \cdot \widehat{\text { comba }}_{i}+\delta \cdot \widehat{\text { casualt }_{i}}+X_{i} B+\epsilon_{i} \\
& =\alpha+\gamma \cdot \widehat{\text { combat }}_{i}+\delta \cdot \text { casualt }_{i}+H_{i} C+X_{i} B+\epsilon_{i}
\end{aligned}
$$

where the combat exposure variables are instrumented with the $z$ 's and the other covariates:

$$
\begin{aligned}
\text { combat }_{i} & =a+b_{1} z_{1}+b_{2} z_{2}+X_{i} B+\nu_{i} \\
\text { casuality }_{i} & =c+d_{1} z_{1}+d_{2} z_{2}+X_{i} B+\eta_{i} .
\end{aligned}
$$

An obvious limitation to such an approach is that because the sharpest identification derives from the experiences of older veterans, our results must be primarily reflecting the effects of combat at older ages. Impacts on younger veterans could easily differ, and we will have no way of telling whether the difference might be interesting or trivial. Effects of combat may be long-lived and slow to emerge over the life cycle, or they could simply not exist among young veterans, perhaps because they are select volunteers rather than conscripts. These as well as other stories could be consistent with null results on combat or deployment among Post-9/11 veterans combined with positive findings among all veterans. For that reason, it is helpful to estimate equations (4) and (5) by OLS as well as IV, in order to compare OLS estimates across all veterans of the marginal effects of combat with earlier estimates across Post-9/11 veterans only. If OLS results are similar across both groups, it is more plausible that the IV estimates may generalize. 


\section{Effects of deployment to OEF/OIF on outcomes}

\subsection{Simple mean differences}

Table 4 presents average characteristics among Post-9/11 veterans in the 2010 NSV according to whether they reported deployment in support of OEF/OIF, the difference between those averages, and the statistical significance of the difference using an adjusted Wald test (Korn and Graubard, 1990). Averages differ significantly across 12 of the 34 listed characteristics, but 4 of these are basic demographics, and 2 more are branches of service. Of the remaining 6 , the most significant differences are in the combat exposure variables, where deployment appears to have raised the lifetime rates of service in a combat or war zone and exposure to casualties by 73.3 and 37.2 percentage points respectively.

Trends in other characteristics reveal no clear differences in status, but several are worth noting. There is limited evidence of different marital status, with a slightly lower rate of never-married and a large but insignificant increase in the rate of being divorced among deployed veterans. Household income is lower among the deployed, but they are also younger by 3 years on average. Rates of being unemployed are very high among both groups, at 18.2 and 19.1 percent among those not deployed versus those deployed. These are rates among all veterans and are slightly lower than official unemployment rates. ${ }^{12}$ The share not in the labor force due to disability is 4.5 percentage points lower among veterans who deployed, and while statistically insignificant, their VA disability ratings are 3.2 percentage points lower as well, suggesting selection by physical ability. Levels of educational attainment are indistinguishable, but higher shares of the deployed had used VA educational benefits and had completed the training or degree that was subsidized. There are no statistically significant differences in health status, although the point estimates revealing the deployed to be slightly healthier. Smoking is slightly more prevalent among those deployed, but again the differences are insignificant.

\footnotetext{
${ }^{12}$ The official definition of the unemployment rate is the number of unemployed divided by the sum of the employed plus the unemployed. Calculated that way, unemployment rates of non-deployed and deployed veterans in the $2010 \mathrm{NSV}$ are 21.3 and 21.9 percent respectively.
} 
Table 4: Average characteristics of Post-9/11 veterans by deployment to OEF/OIF

\begin{tabular}{|c|c|c|c|}
\hline Characteristic & $\begin{array}{l}\text { Not deployed } \\
\text { to OEF/OIF }\end{array}$ & $\begin{array}{r}\text { Deployed } \\
\text { to OEF/OIF }\end{array}$ & $\begin{aligned} & \text { Difference } \\
&= \text { "effect" of } \\
& \text { deployment }\end{aligned}$ \\
\hline Year of birth & 1970.7 & 1973.8 & $3.1^{* * *}$ \\
\hline Percent male & 74.9 & 87.3 & $12.4^{* * *}$ \\
\hline Percent African American & 25.6 & 16.3 & $-9.3^{*}$ \\
\hline Percent Hispanic & 7.2 & 12.6 & $5.3^{*}$ \\
\hline Percent married & 61.0 & 60.5 & -0.5 \\
\hline Percent never married & 25.0 & 24.1 & $-0.9 * *$ \\
\hline Percent divorced & 12.4 & 15.3 & 2.9 \\
\hline Number of dependent children & 1.17 & 1.13 & -0.05 \\
\hline Household income plus transfers & $\$ 67,266$ & $\$ 63,690$ & $-\$ 3,577$ \\
\hline Log household income plus transfers & 10.79 & 10.72 & -0.07 \\
\hline Percent employed & 67.2 & 68.0 & 0.8 \\
\hline Percent unemployed & 18.2 & 19.1 & 0.9 \\
\hline Percent not in labor force due to disability & 5.8 & 1.4 & $-4.5^{* *}$ \\
\hline Percent not in labor force, other & 8.7 & 11.5 & 2.8 \\
\hline Percent owns home & 50.4 & 52.2 & 1.8 \\
\hline Percent with any capital income & 35.3 & 31.0 & -4.3 \\
\hline Percent Internet at home & 89.4 & 92.4 & 3.0 \\
\hline Years of education & 14.3 & 14.1 & -0.2 \\
\hline Percent used any VA educational benefits & 37.9 & 46.6 & $8.6^{*}$ \\
\hline Percent completed VA-subsidized education & 37.3 & 51.5 & $14.2^{*}$ \\
\hline Self-reported health status $(1=$ excellent, $5=$ poor $)$ & 2.64 & 2.59 & -0.04 \\
\hline Percent in fair or poor health & 18.2 & 14.5 & -3.8 \\
\hline Percent needing aid \& attendance & 4.3 & 2.9 & -1.4 \\
\hline Sum of any difficulty on 11 ADLs & 0.57 & 0.56 & -0.01 \\
\hline Average VA disability rating & 16.7 & 13.5 & -3.2 \\
\hline Percent smoked cigarettes ever & 43.0 & 46.4 & 3.5 \\
\hline Percent smoking cigarettes now & 20.1 & 24.8 & 4.7 \\
\hline Percent Army & 35.0 & 47.4 & $12.4^{* *}$ \\
\hline Percent Navy & 22.2 & 20.6 & -1.6 \\
\hline Percent Air Force & 29.0 & 21.9 & -7.1 \\
\hline Percent Marines & 12.8 & 14.5 & 1.7 \\
\hline Percent Coast Guard & 5.1 & 0.6 & $-4.4^{* *}$ \\
\hline Years on active duty & 10.9 & 9.9 & -1.0 \\
\hline Percent ever served in a combat or war zone & 18.4 & 91.7 & $73.3^{* * *}$ \\
\hline Percent ever exposed to dead, dying, or wounded & 26.3 & 63.6 & $37.2^{* * *}$ \\
\hline
\end{tabular}

Sources: 2010 National Survey of Veterans and author's calculations. The universe is Post-9/11 veterans. Statistics are computed with survey weights. See the text for a discussion of the variables. Asterisks denote statistical significance at the $1 \%(* * *), 5 \%(* *)$, and $10 \%(*)$ level. 
Table 5: Estimates of the causal effects of deployment to OEF/OIF based on propensity score matching

\begin{tabular}{lc} 
& $\begin{array}{c}\text { Marginal } \\
\text { effect of }\end{array}$ \\
Characteristic & -5.0 \\
\hline Married & 3.2 \\
Never married & 2.5 \\
Divorced & \\
& $\$ 5,951$ \\
Household income plus transfers & $0.164^{*}$ \\
Log household income plus transfers & $11.8^{* *}$ \\
Percent employed & -3.5 \\
Percent unemployed & $-6.9^{* *}$ \\
Percent not in labor force due to disability & -1.5 \\
Percent not in labor force, other & 6.3 \\
Percent owns home & 3.5 \\
Percent with any capital income & 3.4 \\
Percent with Internet at home & 0.2 \\
Years of education & $12.9^{* *}$ \\
Percent used any VA educational benefits & $14.8^{*}$ \\
Percent completed VA-subsidized education & 0.00 \\
Self-reported health status (1 = excellent, 5 & -2.9 \\
Percent in fair or poor health & 1.4 \\
Percent needing aid \& attendance & 0.02 \\
Sum of any difficulty on 11 ADLs & -4.7 \\
Average VA disability rating & -4.7 \\
Ever smoke cigarettes & -7.2 \\
Smoke cigarettes now & $74.4^{* * *}$ \\
Percent ever served in a combat or war zone & $36.7^{* * *}$ \\
Percent ever exposed to dead, dying, or wounded & \\
\hline \hline
\end{tabular}

Sources: 2010 National Survey of Veterans and author's calculations. The universe is Post-9/11 veterans. The propensity score matching routine is nearest-neighbor (nnmatch in Stata), based on the following variables: age, sex, race, ethnicity, branch of service, and an estimate of years on active duty based on starting and ending years. Statistics are computed with survey weights. See the text for a discussion of the variables. Asterisks denote statistical significance at the $1 \%(* * *), 5 \%(* *)$, and $10 \%(*)$ level.

\subsection{Differences based on propensity-score matching}

Running a propensity-score algorithm based on nearest-neighbor matching (Abadie et al., 2004) corrects for systematic differences in outcomes by observable characteristics, in particular age, sex, race, ethnicity, and branch of service, and it may reveal a causal treatment effect if the observables capture selection mechanisms. Table 5 displays average treatment effects of deployment on socioeconomic and health outcomes based on this method.

Compared to Table 4, many marginal effects remain insignificant. The most interesting developments here are that the effects on household income and log household income have switched signs, and the latter is now statistically significant at the $10 \%$ level and large at 0.164. The propensity score match corrects for the differences we saw in Table 4 across 
several demographic characteristics that are normally correlated with income. Household income plus transfers could be higher because of increased work or wages, or because of increased transfers. The effect of deployment on employment is now positive and significant, while the effect on not being in the labor force due to disability is negative and significant, as before.

Other results are also similar to findings in Table 4. Deployment appears to stimulate effective use of VA educational benefits, there are no clear effects on health or disability, and effects on combat exposure are again large and significant. The most consistent finding across Tables 4 and 5 is that deployment in support of OEF/OIF significantly raises combat exposure.

\subsection{Determinants of combat exposure}

Table 6 further explores the relationship between deployment to OEF/OIF and combat exposure by presenting coefficients from multivariate regressions of the combat exposure variables and VA disability on a set of likely determinants, shown along the rows. Even after accounting for other individual and service characteristics, these models suggest deployment raises the probabilities of service in a combat or war zone and of exposure to casualties by 70.5 and 35.5 percentage points, roughly the same point estimates in Tables 4 and 5. By contrast, VA disability ratings are only weakly related to deployment, and the marginal effect is negative, probably reflecting some reverse causality; service members with higher disability ratings are less likely to be deployed. When exposure to casualties is included in the VA disability rating regression, it has a large and significant positive effect, an increase of 6.9 percentage points. Taken together, these results are consistent with the view that deployment causes combat exposure, and combat exposure causes VA disability and probably other outcomes as well. 
Table 6: Determinants of exposure to combat and casualties and of VA disability among Post-9/11 veterans

\begin{tabular}{lcccc} 
& \multicolumn{3}{c}{ Endogenous variable } \\
\cline { 2 - 5 } Covariate & $\begin{array}{c}\text { Ever served } \\
\text { in a combat } \\
\text { or war zone }\end{array}$ & $\begin{array}{c}\text { Ever exposed } \\
\text { to dead, dying } \\
\text { or wounded }\end{array}$ & $\begin{array}{c}\text { VA } \\
\text { disability } \\
\text { rating }\end{array}$ & $\begin{array}{c}\text { VA } \\
\text { disability } \\
\text { rating }\end{array}$ \\
\hline Deployed to OEF/OIF & $0.705^{* * *}$ & $0.355^{* * *}$ & -0.044 & $-0.065^{*}$ \\
Age & $-0.004^{*}$ & $-0.005^{*}$ & -0.002 & -0.002 \\
Female & $-0.104^{*}$ & $-0.205^{* * *}$ & 0.025 & 0.044 \\
African American & 0.002 & -0.111 & 0.073 & $0.075^{*}$ \\
Hispanic & $0.067^{*}$ & -0.033 & -0.002 & 0.004 \\
Years of education & $0.016^{*}$ & $0.023^{*}$ & -0.004 & -0.006 \\
Navy & 0.063 & $-0.188^{* * *}$ & -0.028 & -0.020 \\
Air Force & -0.068 & $-0.265^{* * *}$ & $-0.066^{*}$ & -0.044 \\
Marines & 0.066 & $-0.136^{*}$ & -0.015 & -0.002 \\
Coast Guard & $-0.243^{* * *}$ & 0.137 & -0.105 & -0.111 \\
Years on active duty & $0.007^{* * *}$ & 0.005 & $0.009^{* * *}$ & $0.010^{* * *}$ \\
Ever served in a combat or war zone & & & -0.002 \\
Ever exposed to dead/dying/wounded & & & & $0.069^{* *}$ \\
\hline \hline
\end{tabular}

Sources: 2010 National Survey of Veterans and author's calculations. The universe is Post-9/11 veterans. Each column reports ordinary least squares (OLS) estimates of a separate regression of the endogenous variable in the column on the covariates shown along the rows. Regressions are estimated with survey weights. See the text for a discussion of the variables. Asterisks denote statistical significance at the $1 \%(* * *), 5 \%(* *)$, and $10 \%(*)$ level.

\section{Effects of exposure to combat and casualties on out- comes}

\section{$5.1 \quad$ Post-9/11 veterans}

Table 7 and 8 report coefficients from nested multivariate regressions of outcomes on deployment to OEF/OIF, combat exposure, health, VA disability, and controls. As before, many of the marginal effects on these outcomes are insignificant. But the tables also reveal that for every outcome, deployment to OEF/OIF loses any significance it may have had once the combat exposure variables are introduced. In a simple horse race, combat exposure wins because it is more tightly correlated with outcomes than is deployment. Even controlling for self-reported health status on a five-point scale and for the VA disability rating, both of which are often significant, does not in general reduce the significance of the combat exposure variables in these regressions.

Still, Table 7 offers relatively limited evidence of any impacts of deployment or combat on current socioeconomic outcomes among Post-9/11 veterans. Veterans who deployed or were exposed to combat were between 5 and 10 percent more likely to be divorced. Effects on 
Table 7: Marginal effects of deployment, exposure to combat and casualties, and health on socioeconomic outcomes among Post-9/11 veterans based on cross-sectional variation

\begin{tabular}{|c|c|c|c|c|c|}
\hline Endogenous variable & $\begin{array}{c}\text { Deployed to } \\
\text { OEF/OIF }\end{array}$ & $\begin{array}{l}\text { Ever served } \\
\text { in a combat } \\
\text { or war zone }\end{array}$ & $\begin{array}{l}\text { Ever exposed } \\
\text { to dead, dying } \\
\text { or wounded }\end{array}$ & $\begin{array}{l}\text { Self-reported } \\
\text { health status }\end{array}$ & $\begin{array}{c}\text { VA disability } \\
\text { rating }\end{array}$ \\
\hline Married or partnered & $\begin{array}{l}-0.056 \\
-0.058 \\
-0.056\end{array}$ & $\begin{array}{l}0.047 \\
0.041\end{array}$ & $\begin{array}{l}-0.090 \\
-0.081\end{array}$ & 0.011 & -0.102 \\
\hline Divorced or separated & $\begin{array}{l}0.069^{*} \\
0.009 \\
0.001\end{array}$ & $\begin{array}{l}0.043^{*} \\
0.052^{*}\end{array}$ & $\begin{array}{l}0.075^{*} \\
0.075^{*}\end{array}$ & -0.029 & 0.058 \\
\hline $\begin{array}{l}\text { Log household income } \\
\text { plus transfers }\end{array}$ & $\begin{array}{l}0.046 \\
0.094 \\
0.091\end{array}$ & $\begin{array}{l}-0.060 \\
-0.041\end{array}$ & $\begin{array}{l}0.010 \\
0.064\end{array}$ & $-0.181^{* * *}$ & $0.307^{* *}$ \\
\hline Unemployed & $\begin{array}{l}-0.062 \\
-0.017 \\
-0.022\end{array}$ & $\begin{array}{l}-0.055 \\
-0.059\end{array}$ & $\begin{array}{l}-0.022 \\
-0.021\end{array}$ & 0.030 & $-0.169 * *$ \\
\hline $\begin{array}{l}\text { Not in labor force due } \\
\text { to disability }\end{array}$ & $\begin{array}{l}-0.052^{* *} \\
-0.047^{* *} \\
-0.027\end{array}$ & $\begin{array}{l}-0.024 \\
-0.033\end{array}$ & $\begin{array}{r}0.030 \\
-0.003\end{array}$ & $0.047^{* * *}$ & $0.213^{* * *}$ \\
\hline Not in labor force, other & $\begin{array}{r}0.015 \\
-0.012 \\
-0.002\end{array}$ & $\begin{array}{l}0.049 \\
0.049\end{array}$ & $\begin{array}{l}-0.025 \\
-0.034\end{array}$ & -0.007 & $0.181 * * *$ \\
\hline Owns home & $\begin{array}{l}0.047 \\
0.009 \\
0.009\end{array}$ & $\begin{array}{l}0.078 \\
0.078\end{array}$ & $\begin{array}{l}-0.027 \\
-0.039\end{array}$ & 0.016 & 0.101 \\
\hline Any capital income & $\begin{array}{r}0.036 \\
0.001 \\
-0.025\end{array}$ & $\begin{array}{l}0.103^{* *} \\
0.117\end{array}$ & $\begin{array}{l}-0.116^{* *} \\
-0.095\end{array}$ & -0.037 & -0.083 \\
\hline Internet at home & $\begin{array}{l}0.020 \\
0.062 \\
0.061\end{array}$ & $\begin{array}{l}-0.084 \\
-0.082\end{array}$ & $\begin{array}{l}0.048 \\
0.063\end{array}$ & -0.038 & 0.059 \\
\hline Years of education & $\begin{array}{r}0.178 \\
-0.213 \\
-0.292 \\
\end{array}$ & $\begin{array}{l}0.329 \\
0.361^{* *}\end{array}$ & $\begin{array}{l}0.361 \\
0.494^{* *}\end{array}$ & $-0.377^{* * *}$ & -0.206 \\
\hline
\end{tabular}

Sources: 2010 National Survey of Veterans and author's calculations. The universe is Post-9/11 veterans. Each row reports ordinary least squares (OLS) estimates of a separate regression of the endogenous variable in the row on the covariates shown along the columns and a set of controls for demographic characteristics and branch of service. See Table 3 for a detailed list of controls. Regressions are estimated with survey weights. See the text for a discussion of the variables. Asterisks denote statistical significance at the $1 \%(* * *), 5 \%(* *)$, and $10 \%(*)$ level. 
Table 8: Marginal effects of deployment and exposure to combat and casualties on health outcomes among Post-9/11 veterans based on cross-sectional variation

\begin{tabular}{|c|c|c|c|c|}
\hline Endogenous variable & $\begin{array}{l}\text { Deployed to } \\
\text { OEF/OIF }\end{array}$ & $\begin{array}{l}\text { Ever served } \\
\text { in a combat } \\
\text { or war zone }\end{array}$ & $\begin{array}{l}\text { Ever exposed } \\
\text { to dead, dying } \\
\text { or wounded }\end{array}$ & $\begin{array}{l}\text { VA disability } \\
\text { rating }\end{array}$ \\
\hline Self-reported health status & 0.110 & & & \\
\hline \multirow[t]{2}{*}{$(1=$ excellent, $5=$ poor $)$} & -0.134 & $0.128^{* * *}$ & $0.424 * * *$ & \\
\hline & -0.051 & $0.124^{* * *}$ & $0.330 * * *$ & $1.427 * * *$ \\
\hline \multirow[t]{3}{*}{ Fair or poor health } & -0.010 & & & \\
\hline & -0.013 & $-0.076^{* * *}$ & $0.173^{* * *}$ & \\
\hline & 0.022 & $-0.081 * * *$ & $0.140 * * *$ & $0.537 * * *$ \\
\hline \multirow[t]{3}{*}{ Needs aid \& attendance } & 0.010 & & & \\
\hline & -0.007 & $0.004^{*}$ & $0.031^{*}$ & \\
\hline & 0.005 & 0.003 & 0.020 & $0.179 * * *$ \\
\hline \multirow[t]{3}{*}{ Sum of any difficulty on 11 ADLs } & -0.058 & & & \\
\hline & 0.003 & -0.163 & 0.101 & \\
\hline & 0.122 & -0.166 & -0.023 & $1.918^{* * *}$ \\
\hline \multirow[t]{3}{*}{ Ever smoked cigarettes } & 0.051 & & & \\
\hline & 0.037 & -0.030 & 0.066 & \\
\hline & 0.044 & -0.033 & 0.063 & 0.077 \\
\hline \multirow[t]{3}{*}{ Currently smokes cigarettes } & 0.014 & & & \\
\hline & -0.035 & 0.093 & -0.061 & \\
\hline & -0.030 & 0.092 & -0.067 & 0.079 \\
\hline
\end{tabular}

Sources: 2010 National Survey of Veterans and author's calculations. The universe is Post-9/11 veterans. Each row reports ordinary least squares (OLS) estimates of a separate regression of the endogenous variable in the row on the covariates shown along the columns and a set of controls for demographic characteristics and branch of service. See Table 3 for a detailed list of controls. Regressions are estimated with survey weights. See the text for a discussion of the variables. Asterisks denote statistical significance at the $1 \%(* * *), 5 \%(* *)$, and $10 \%(*)$ level. 
household income are insignificant although occasionally large, but there are large impacts of self-reported health status and VA disability on income, and they work in opposite directions. For each step on the five-point scale toward worse health, these veterans report 18.1 percent less income, while an increase of 10 percentage points in the VA disability rating is associated with an increase in income of about 3 percent. This contrasts with the jointly positive effects of both these variables on the probability of being out of the labor force due to disability, and it reveals the operation of the system of VA disability compensation.

Table 8 reveals some evidence of health impacts. Self-reported health is strongly associated with both combat exposure variables, as is reporting either fair or poor health status, and these effects exist independently of the VA disability rating. But service in a combat or war zone is protective against fair or poor health, even though it tends to decrease selfreported health status overall, while exposure to casualties is bad for self-reported health in either sense and much worse than service in a war zone. In the rest of the table, there is little evidence that disability or smoking responds at all to combat exposure.

These findings concerning combat and self-reported health are interesting for three reasons. First, we suspect that self-reported health status summarizes perceptions of mental as well as physical health, while the disability measures solely measure the latter. These results suggest that deployment and combat may have harmed the mental health of OEF/OIF veterans, consistent with the findings of Cesur, Sabira and Tekin (2011) and others, although they are far from conclusive. Second, it is interesting that combat reduces self-reported health but not household income, which is itself reduced by worsened self-reported health. Offsetting influences such as disability compensation must be strong enough to negate the effect of combat on income. Third, the protective influence of service in a combat or war zone against being in fair or poor health is noteworthy because of its contrast with the harmful effect of exposure to casualties. Differing magnitudes or opposing signs are reassuring indicators that these variables are measuring real influences whose effects could naturally differ. Service in a war zone without exposure to casualties could be a positive influence if it provides feelings of optimism, satisfaction, or invincibility, while exposure to casualties seems likely to be a negative influence regardless of context. 


\subsection{All veterans}

A pattern of countervailing effects on socioeconomic status of service in a combat zone versus exposure to casualties is more evident in Tables 9 and 10, which present regression coefficients estimated over the entire pool of surviving veterans sampled in the $2010 \mathrm{NSV}$. In almost every case where the combat exposure variables are significant in these tables, service in a combat or war zone appears to improve outcomes by some amount while exposure to casualties worsens them by an equal or larger amount. Sometimes signs and significance changes with the estimation strategy, and magnitudes often change, but this general result appears to persist.

For example, OLS results indicate that the probability the veteran is married rises by 3.2 to 3.4 percentage points with service in a combat or war zone, but it declines by 3 to 4 percentage points with exposure to dead, dying, or wounded people. The net effect is roughly zero for the 23.2 percent of veterans reporting both, as shown in Table 2. The IV estimates of these effects are about ten times larger than the OLS estimates, which could reflect attenuation bias stemming from measurement error in individual combat exposure variables. In the case of divorce, war zone exposure is protective while casualties increase it, with the effects again netting out to zero for veterans reporting both.

As was the case with the subset of Post-9/11 veterans, there is no evidence here of any impact of combat exposure on household income, here among all veterans. Health status and VA disability are still important in the same ways as before, but combat exposure has no effect in either the OLS or IV results, further evidence that the disability compensation system is effective at replacing income.

Effects on employment status are somewhat less meaningful among all veterans since the median age in the data is 65 and many are retired. Most of those who are not in the labor force due to reasons other than disability are retired. Results in Table 9 indicate that war zone service increases the probability of retirement while exposure to casualties reduces it by more. Part of this could be connected to patterns in homeownership and capital income, both of which are reduced by exposure to casualties. Effects of combat exposure on educational attainment are unclear, with roughly offsetting OLS results that are not 
Table 9: Marginal effects of deployment, exposure to combat and casualties, and health on socioeconomic outcomes among all veterans based on cross-sectional and birth-cohort variation

\begin{tabular}{|c|c|c|c|c|c|}
\hline Endogeous variable & Model & $\begin{array}{l}\text { Ever served } \\
\text { in a combat } \\
\text { or war zone }\end{array}$ & $\begin{array}{l}\text { Ever exposed } \\
\text { to dead, dying } \\
\text { or wounded }\end{array}$ & $\begin{array}{l}\text { Self-reported } \\
\text { health status }\end{array}$ & $\begin{array}{l}\text { VA disability } \\
\text { rating }\end{array}$ \\
\hline \multirow[t]{4}{*}{ Married or partnered } & OLS & $0.032^{*}$ & $-0.040^{* *}$ & & \\
\hline & IV & $0.291 * *$ & $-0.299^{*}$ & & \\
\hline & OLS & $0.034^{*}$ & $-0.030^{*}$ & $-0.028 * * *$ & -0.057 \\
\hline & IV & $0.283^{*}$ & $-0.290^{*}$ & $-0.024^{* * *}$ & -0.050 \\
\hline \multirow[t]{4}{*}{ Divorced or separated } & OLS & -0.018 & $0.028 * *$ & & \\
\hline & IV & $-0.249 * *$ & $0.284^{* *}$ & & \\
\hline & OLS & -0.020 & 0.023 & $0.015^{* * *}$ & 0.065 \\
\hline & IV & $-0.259^{* *}$ & $0.301 * *$ & 0.010 & 0.049 \\
\hline \multirow{4}{*}{$\begin{array}{l}\text { Log household income } \\
\text { plus transfers }\end{array}$} & OLS & -0.027 & -0.023 & & \\
\hline & IV & 0.210 & 0.025 & & \\
\hline & OLS & -0.014 & 0.029 & $-0.470 * * *$ & $0.637^{* * *}$ \\
\hline & IV & 0.102 & 0.167 & $-0.179^{* * *}$ & 0.123 \\
\hline \multirow[t]{4}{*}{ Unemployed } & OLS & -0.004 & 0.006 & & \\
\hline & IV & 0.007 & -0.079 & & \\
\hline & OLS & -0.002 & 0.010 & $0.010^{* *}$ & $-0.091^{* * *}$ \\
\hline & IV & 0.022 & -0.094 & $0.014^{* *}$ & $-0.068^{* *}$ \\
\hline \multirow{4}{*}{$\begin{array}{l}\text { Not in labor force due } \\
\text { to disability }\end{array}$} & OLS & 0.011 & $0.023^{* * *}$ & & \\
\hline & IV & -0.096 & 0.149 & & \\
\hline & OLS & -0.006 & 0.003 & $0.049^{* * *}$ & $0.309 * * *$ \\
\hline & IV & -0.088 & 0.123 & $0.046^{* * *}$ & $0.296^{* * *}$ \\
\hline \multirow{4}{*}{ Not in labor force, other } & OLS & $0.034^{* *}$ & $-0.031^{* *}$ & & \\
\hline & IV & $0.441^{* * *}$ & $-0.699 * * *$ & & \\
\hline & OLS & $0.028 * *$ & $-0.037^{* * *}$ & 0.003 & $0.097^{* *}$ \\
\hline & IV & $0.434^{* * *}$ & $-0.705^{* * *}$ & $0.019^{* *}$ & $0.179^{* * *}$ \\
\hline \multirow[t]{4}{*}{ Owns home } & OLS & $0.045^{* * *}$ & $-0.033^{* *}$ & & \\
\hline & IV & $0.378 * * *$ & $-0.306^{*}$ & & \\
\hline & OLS & $0.044^{* * *}$ & $-0.028^{*}$ & $-0.015^{* *}$ & 0.051 \\
\hline & IV & $0.366^{* *}$ & $-0.290^{*}$ & $-0.013^{*}$ & 0.039 \\
\hline \multirow[t]{4}{*}{ Any capital income } & OLS & -0.002 & $-0.054^{* * *}$ & & \\
\hline & IV & 0.016 & -0.071 & & \\
\hline & OLS & 0.009 & $-0.043^{* *}$ & $-0.040 * * *$ & $-0.118^{* * *}$ \\
\hline & IV & 0.011 & -0.040 & $-0.040^{* * *}$ & $-0.119 * * *$ \\
\hline \multirow[t]{4}{*}{ Internet at home } & OLS & 0.015 & -0.017 & & \\
\hline & IV & -0.184 & 0.256 & & \\
\hline & OLS & 0.012 & -0.010 & $-0.029 * * *$ & $0.074^{*}$ \\
\hline & IV & -0.219 & 0.310 & $-0.036^{* * *}$ & 0.046 \\
\hline \multirow[t]{4}{*}{ Years of education } & OLS & $-0.318^{* * *}$ & $0.140 *$ & & \\
\hline & IV & 0.833 & -0.644 & & \\
\hline & OLS & $-0.220^{* * *}$ & $0.250^{* * *}$ & $-0.576^{* * *}$ & 0.038 \\
\hline & IV & 0.514 & -0.035 & $-0.588^{* * *}$ & -0.082 \\
\hline
\end{tabular}

Sources: 2010 National Survey of Veterans and author's calculations. The universe is all veterans. Each row reports estimates of a separate regression of the endogenous variable in the row on the covariates shown along the columns and a set of controls for demographic characteristics and branch of service. See Table 3 for a detailed list of controls. Models are estimated by ordinary least squares (OLS) or instrumental variables (IV). The IV regressions are two-stage least squares procedures that instrument for exposures to combat and casualties using exposures reported by the birth cohort. All regressions are estimated with survey weights. See the text for a discussion of the variables and estimation strategy. Asterisks denote statistical significance at the $1 \%$ ( $* * *)$, $5 \%$ $(* *)$, and $10 \%(*)$ level. 
Table 10: Marginal effects of deployment and exposure to combat and casualties on health outcomes among all veterans based on cross-sectional and birth-cohort variation

\begin{tabular}{|c|c|c|c|c|}
\hline Endogenous variable & Model & $\begin{array}{l}\text { Ever served } \\
\text { in a combat } \\
\text { or war zone }\end{array}$ & $\begin{array}{l}\text { Ever exposed } \\
\text { to dead, dying } \\
\text { or wounded }\end{array}$ & $\begin{array}{l}\text { VA disability } \\
\text { rating }\end{array}$ \\
\hline \multirow{4}{*}{$\begin{array}{l}\text { Self-reported health status } \\
(1=\text { excellent, } 5=\text { poor })\end{array}$} & OLS & $0.110^{* * *}$ & $0.210^{* * *}$ & \\
\hline & IV & -0.374 & 0.800 & \\
\hline & OLS & $0.066^{*}$ & $0.161^{* * *}$ & $1.279^{* * *}$ \\
\hline & IV & -0.426 & $0.824^{*}$ & $1.204^{* * *}$ \\
\hline \multirow[t]{4}{*}{ Fair or poor health } & OLS & 0.027 & $0.098^{* * *}$ & \\
\hline & IV & -0.142 & $0.355^{* *}$ & \\
\hline & OLS & 0.008 & $0.078^{* * *}$ & $0.532^{* * *}$ \\
\hline & IV & -0.164 & $0.359^{* *}$ & $0.489^{* * *}$ \\
\hline \multirow[t]{4}{*}{ Needs aid \& attendance } & OLS & -0.006 & $0.046^{* * *}$ & \\
\hline & IV & -0.107 & $0.228^{*}$ & \\
\hline & OLS & -0.011 & $0.037^{* * *}$ & $0.191^{* * *}$ \\
\hline & IV & -0.103 & $0.221^{*}$ & $0.157^{* * *}$ \\
\hline \multirow[t]{4}{*}{ Sum of any difficulty on 11 ADLs } & OLS & -0.001 & $0.314^{* * *}$ & \\
\hline & IV & -1.574 & $2.193^{*}$ & \\
\hline & OLS & -0.054 & $0.238^{* * *}$ & $1.769^{* * *}$ \\
\hline & IV & $-1.678^{*}$ & $2.279^{* *}$ & $1.569^{* * *}$ \\
\hline \multirow[t]{4}{*}{ Ever smoked cigarettes } & OLS & 0.001 & $0.047^{* * *}$ & \\
\hline & IV & 0.043 & -0.113 & \\
\hline & OLS & 0.000 & $0.044^{* *}$ & 0.028 \\
\hline & IV & 0.038 & -0.126 & 0.074 \\
\hline \multirow[t]{4}{*}{ Currently smokes cigarettes } & OLS & -0.024 & 0.022 & \\
\hline & IV & $-0.396^{* *}$ & $0.350^{*}$ & \\
\hline & OLS & -0.022 & 0.017 & 0.024 \\
\hline & IV & $-0.391^{* *}$ & 0.337 & 0.028 \\
\hline
\end{tabular}

Sources: 2010 National Survey of Veterans and author's calculations. The universe is all veterans. Each row reports estimates of a separate regression of the endogenous variable in the row on the covariates shown along the columns and a set of controls for demographic characteristics and branch of service. See Table 3 for a detailed list of controls. Models are estimated by ordinary least squares (OLS) or instrumental variables (IV). The IV regressions are two-stage least squares procedures that instrument for exposures to combat and casualties using exposures reported by the birth cohort. All regressions are estimated with survey weights. See the text for a discussion of the variables and estimation strategy. Asterisks denote statistical significance at the $1 \%$ ( $* * *), 5 \%$ $(* *)$, and $10 \%(*)$ level. 
confirmed by the IV estimates.

Table 10 shows that service in a combat or war zone does not in general have much of a protective effect on health, while exposure to dead, dying, or wounded people appears to be robustly harmful. We see both self-reported health and indicators of disability worsening with exposure to casualties, irrespective of controlling for the VA disability rating, which is also significant across the board. Effects on smoking change sign and significance, but there are some indications that past service in a war zone may be protective against smoking, while exposure to casualties may increase it.

\section{Conclusion}

Understanding the effects of deployment on military service members and their families is an important task for research and policy, and the 2010 National Survey of Veterans provides new insights. It is the first public survey of veterans to ask specifically about deployment in support of Operation Enduring Freedom (OEF) and Operation Iraqi Freedom (OIF), the two major conflicts thus far in the 21st century, and it measures combat exposure along two dimensions that are empirically linked to outcomes: service in a combat or war zone; and exposure to dead, dying, or wounded people.

As one might expect, deployment to OEF/OIF is associated with service in a war zone and to exposure to casualties. In particular, deployment appears to raise the probability of each by about 75 and 35 percentage points respectively. The data also support the supposition that deployment causes combat exposure, which in turn causes VA disability ratings and other outcomes. These patterns suggest it is worthwhile to examine how combat exposure in addition to deployment may affect outcomes, an analysis that can be extended to all veterans in the survey in order to gather additional, if necessarily tentative, insights.

Among veterans of the Post-9/11 era, I find statistically insignificant associations between deployment or combat exposure and current socioeconomic outcomes like household income plus transfers or wealth in the form of homeownership or asset earnings. These results are fully consistent with the existence of a disability compensation system that is 
designed to replace lost earnings. I also find statistically significant and deleterious associations between combat and nonpecuniary outcomes like marriage or divorce and self-reported health status, but not on disability. Because self-reported health is likely to measure an average of mental and physical well-being, these results are consistent with those of Cesur, Sabira and Tekin (2011) and others who report mental health trauma among young combat veterans. In conjunction with the findings on household income, which appears not to vary with combat exposure, my results suggest that service-related transfers may replace earnings but may not fully compensate for the harms associated with combat. If they did, we would see combat exposure raising household income or wealth to compensate for the additional harms to health status or marital outcomes.

There are relatively sharp discontinuities in combat exposure across birth cohorts of veterans in the $2010 \mathrm{NSV}$, which appear to be driven by the experiences of conscripts. The timing of major wars and the focused incidence on young men of service and combat prior to the All-Volunteer Force provide a set of natural experiments that can reveal the causal influences of combat exposure on outcomes among older veterans. Exploiting variation in exposure across birth cohorts as an instrumental variable for self-reported combat exposure should eliminates any econometric problems associated with selection into combat.

Instrumental variables and ordinary least squares estimates of the effects of combat exposure on outcomes among all veterans tend to agree on the signs if not the magnitudes of the effects of combat, which are broader in scope than among young OEF/OIF veterans. Impacts on socioeconomic outcomes are often at least partially offsetting, with service in a war zone often improving outcomes while combat exposure worsens them. A consistent finding across the two samples is that there seems to be no effect of combat on household income, probably because disability compensation offsets it. But impacts of combat on marriage, wealth, and especially health status and disability emerge from the analysis of older veterans. Whether or not they will generalize to the future status of currently younger veterans would be entirely speculative, but it is tempting to conclude that the past will be a guide to the future, especially given the small number of effects that appear already to be shared by the two samples. 
One of the key challenges facing researchers studying veterans is the long-lived nature of effects of military service on outcomes. Based on the experiences of older cohorts of veterans, service-connected disability benefits, which are a good indicator of assessed need, typically peak more than three decades after the end of hostilities (Institute of Medicine, 2010). With at most only 8 years separating the beginning of Post-9/11 hostilities and the point of data collection in the $2010 \mathrm{NSV}$, it is eminently possible that impacts of deployment to $\mathrm{OEF} / \mathrm{OIF}$ are still latent. Effects might also be undetectable because of another challenge facing researchers: low statistical power due to small data samples. There are only 753 veterans of the Post-9/11 era in the 2010 NSV, of whom 565 were deployed to OEF/OIF. Because of these limitations, the estimated effects of deployment should be interpreted with

circumspection. Results are often statistically insignificant, but the typical reason is that the marginal effects have large standard errors, and not that the effects are precisely estimated zeros. Such a pattern might reflect heterogeneity in veterans' experiences, small sample size, a true null effect, or some combination of these.

\section{Acknowledgements}

I am grateful to Tom Garin and Mike Grierson at the U.S. Department of Veterans Affairs, to Cary Haver at the Institute of Medicine for assistance in obtaining and understanding the public file of the 2010 National Survey of Veterans, and to seminar participants at Lafayette College for helpful comments. All analysis, opinions, and any mistakes expressed in this paper are solely my own and do not reflect the perspectives or positions of any other group or institution. I declare no conflicts of interest nor external funding sources. 


\section{References}

Abadie, Alberto, David Drucker, Jane Leber Herr and Guido W. Imbens. 2004. "Implementing matching estimators for average treatment effects in Stata." Stata Journal 4(3):290311.

Angrist, Joshua D. 1990. "Lifetime Earnings and the Vietnam Era Draft Lottery: Evidence from Social Security Administrative Records." American Economic Review 80(3):313-336.

Angrist, Joshua D. 2001. "Estimation of Limited Dependent Variable Models With Dummy Endogenous Regressions: Simple Strategies for Empirical Practice." Journal of Business and Economic Statistics 19(1):2-28.

Angrist, Joshua D. and Alan B. Krueger. 1994. "Why Do World War II Veterans Earn More than Nonveterans?" Journal of Labor Economics 12(1):74-97.

Card, David and Thomas Lemieux. 2001. "Going to College to Avoid the Draft: The Unintended Legacy of the Vietnam War." American Economic Review 91(2):97-102.

Cesur, Resul, Joseph J. Sabira and Erdal Tekin. 2011. "The Psychological Costs of War: Military Combat and Mental Health." NBER Working Paper 16927.

Institute of Medicine. 2007. A 21st Century System for Evaluating Veterans for Disability Benefits. Washington, DC: The National Academies Press.

Institute of Medicine. 2010. Returning Home from Iraq and Afghanistan: Preliminary Assessment of Readjustment Needs of Veterans, Service Members, and Their Families. Washington, DC: The National Academies Press.

Korn, Edward L. and Barry I. Graubard. 1990. "Simultaneous Testing of Regression Coefficients With Complex Survey Data: Use of Bonferroni $t$ Statistics." American Statistician $44(4): 270-276$.

MacLean, Alair and Ryan D. Edwards. 2012. Health, Aging, and the Post-Service Life Cycles of U.S. Veterans. In Military Medical Care: From Pre-Deployment to Post-Separation, ed. Jomana Amara and Ann Hendricks. Routledge, submitted. 
Rohlfs, Chris. 2010. "Does Combat Exposure Make You a More Violent or Criminal Person?" Journal of Human Resources 45(2):271-300.

Rosenbaum, Paul R. and Donald B. Rubin. 1983. "The Central Role of the Propensity Score in Observational Studies for Causal Effects." Biometrika 70(1):41-55.

Ruggles, Steven, J. Trent Alexander, Katie Genadek, Ronald Goeken, Matthew B. Schroeder and Matthew Sobek. 2010. "Integrated Public Use Microdata Series: Version 5.0 [Machine-readable database]." Minneapolis: University of Minnesota.

Smith, Tyler C., Mark Zamorski, Besa Smith, James R. Riddle, Cynthia A. LeardMann, Timothy S. Wells, Charles C. Engel, Charles W. Hoge, Joyce Adkins and Dan Blaze. 2007. "The physical and mental health of a large military cohort: baseline functional health status of the Millennium Cohort." BMC Public Health 7(147):340. doi: 10.1186/14712458-7-340.

Tanielian, Terri and Lisa H. Jaycox, eds. 2008. Invisible Wounds of War: Psychological and Cognitive Injuries, Their Consequences, and Services to Assist Recovery. Santa Monica: RAND Corporation.

Westat. 2010. "National Survey of Veterans, Active Duty Service Members, Demobilized National Guard and Reserve Members, Family Members, and Surviving Spouses." Final Report, Deliverable 27 http://www.va.gov/VETDATA/Surveys.asp. 